\title{
Rancang Bangun Aplikasi Administrasi Perbaikan Kendaraan Pada Vehicle Operation Management Berbasis Web di PT Altrak 1978 Samarinda
}

\author{
Renaldi Anwar $^{1 *}$, Fahrullah $^{2}$, Dedi Mirwansyah ${ }^{3}$ \\ ${ }^{1,2,3}$ Universitas Mulia
}

*renaldi@students.universitasmulia.ac.id

\begin{abstract}
PT ALTRAK 1978 Samarinda is a large branch that has several departments, including $H R \& G A, F A$, Marketing, Part, Rebuild Center, Service and VOM (Vehicle Operation Management). The task of VOM is to maintain, repair and manage all operational vehicle assets owned by PT ALTRAK 1978 at 10 Depos in the Kalimantan area, and one of the tasks of VOM is to create reports for all processes carried out at VOM and everything related to company operational vehicles, but many reports are made that require data from vehicle repairs such as operational vehicle repair history. When retrieving data from the repair history, we always experience difficulties because the data is incomplete and not integrated between several parts at PT ALTRAK 1978 Samarinda and until now, if there are complaints about damage to operational vehicles, vehicle users still experience problems when they want to report damage to these vehicles because there is no administration system in every vehicle repair administration process. The formulation of the problem is how to make it easier for VOM to report vehicle repairs with a data source or repair history that can be seen and retrieved easily by several parties involved in the vehicle repair administration process with the aim of making it easier for VOM and vehicle users to receive and report vehicle damage quickly and in an integrated manner. each other between several departments.
\end{abstract}

Keywords: vehicle repair's application, vehicle operation management

\begin{abstract}
Abstrak
PT ALTRAK 1978 Samarinda adalah cabang besar yang memiliki beberapa departemen, diantarannya HR\&GA, FA, Marketing, Part, Rebuild Center, Service dan VOM (Vehicle Operation Management). Tugas dari VOM untuk merawat, memperbaiki dan me-manage seluruh aset kendaraan operasional milik PT ALTRAK 1978 pada 10 Depo di area Kalimantan, dan salah satu tugas dari VOM adalah membuat laporan untuk semua proses yang dikerjakan pada VOM dan semua yang berhubungan dengan kendaraan operasional perusahaan, namun banyaknya laporan yang dibuat yang membutuhkan data dari perbaikan kendaraan seperti riwayat perbaikan kendaraan operasional. Pada saat mengambil data dari riwayat perbaikan selalu mengalami kesulitan karena data yang tidak lengkap dan tidak terintegrasi anatara beberapa bagian di PT ALTRAK 1978 Samarinda dan hingga saat ini jika ada keluhan mengenai kerusakan pada kendaraan operasional para pengguna kendaraan masih mengalami masalah pada saat ingin melaporkan kerusakan pada kendaraan tersebut karena tidak adanya sistem administrasi dalam setiap proses administrasi perbaikan kendaraan. Rumusan masalahnya ialah bagaimana memudahkan VOM untuk melakukan pelaporan perbaikan kendaraan dengan sumber data atau histori perbaikan dapat dilihat dan diambil dengan mudah oleh beberapa pihak yang berhubungan dalam proses administrasi perbaikan kendaraan dengan tujuan memudahkan VOM dan pengguna kendaraan untuk menerima dan melaporkan kerusakan kendaraan secara cepat dan terintegrasari satu sama lain antar beberapa departemen.
\end{abstract}

Kata kunci: aplikasi administrasi perbaikan kendaraan, vehicle Operation Management

\section{Pendahuluan}

Di zaman globalisasi seperti sekarang, Teknologi Informasi dan komputerisasi semakin berkembang dengan cepat, sehingga membuat segala sesuatu menjadi serba otomatis dan cepat termasuk dalam proses administrasi perbaikan kendaraan. PT ALTRAK 1978 Samarinda adalah cabang 
besar yang memiliki beberapa departemen, diantarannya HR\&GA, FA, Marketing, Part, Rebuild Center, Service dan VOM (Vehicle Operation Management. Tugas dari VOM untuk merawat, memperbaiki dan me-manage seluruh aset kendaraan operasional milik PT ALTRAK 1978 pada 10 Depo di area Kalimantan, dan salah satu tugas dari VOM adalah membuat laporan untuk semua proses yang dikerjakan pada VOM dan semua yang berhubungan dengan kendaraan operasional perusahaan, namun banyaknya laporan yang dibuat yang membutuhkan data dari perbaikan kendaraan seperti riwayat perbaikan kendaraan operasional. Berdasarkan hasil observasi, pada saat mengambil data dari riwayat perbaikan selalu mengalami kesulitan karena data yang tidak lengkap dan tidak terintegrasi anatara beberapa bagian di PT ALTRAK 1978 Samarinda dan hingga saat ini jika ada keluhan mengenai kerusakan pada kendaraan operasional para pengguna kendaraan masih mengalami masalah pada saat ingin melaporkan kerusakan pada kendaraan tersebut karena tidak adanya sistem administrasi dalam setiap proses administrasi perbaikan kendaraan. Proses yang berjalan saat ini untuk melakukan proses administrasi mulai dari user melaporkan kerusakan hingga proses perbaikan selesai masih menggunakan form dan aplikasi Microsoft Excel. Adapun tujuan penelitian ini adalah:

a. Memudahkan VOM dan pengguna kendaraan untuk menerima dan melaporkan kerusakan kendaraan secara cepat dan terintegrasari satu sama lain antar beberapa departemen.

b. Merancang aplikasi administrasi perbaikan kendaraan yang dilakukan secara komputerisasi, sehingga dapat terintegrasi.

c. Memudahkan user dalam melaporkan kerusakan kendaraan kepada VOM.

Sistem informasi merupakan suatu sistem didalam suatu organisasi yang mempertemukan kebutuhan pengolahan transaksi harian, mendukung operasi, bersifat menejerial dengan kegiatan strategi dari suatu organisasi agar dapat menyediakan laporanlaporan yang diperlukan untuk pihak luar [1].
PHP adalah bahasa server-sidescripting yang menyatu dengan HTML untuk membuat halaman web yang dinamis dan PHP merupakan server-side-scripting maka sintaks dan perintah PHP akan diesksekusi diserver kemudian hasilnya akan dikirimkan ke browser dengan format HTML [2].

Web adalah suatu sistem yang berkaitan dengan dokumen digunakan sebagai media untuk menampilkan teks, gambar, multimedia, dan lainnya pada jaringan internet" [3].

Secara etimologis "administrasi" berasal dari bahasa latin, yaitu kata ad dan ministrare. Kata ad artinya intensif, sedangkan ministrare artinya melayani, membantu, atau mengarahkan. Jadi pengertian administrasi adalah melayani secara insentif [4].

Pengertian dari perbaikan itu sendiri adalah usaha untuk mengembalikan kondisi dan fungsi dari suatu benda atau alat yang rusak akibat pemakaian alat tersebut pada kondisi semula [5].

\section{Metoda Penelitian}

\subsection{Metode pengumpulan data}

Metode pengumpulan data yang dilakukan untuk mengumpulkan data adalah sebagai berikut:

\subsubsection{Analisis}

Melakukan analisis terhadap permasalahan yang terjadi dan melihat kebutuhan dari sistem yang akan dibuat untuk menyelesaikan permasalahan. Dimulai dengan melakukan analisis dan mengumpulkan data serta informasi terhadap proses yang sudah berjalan. Kemudian membuat sebuah alur proses.

\subsubsection{Observasi}

Mengamati proses sistem administrasi perbaikan kendaraan yang berjalan dan mengumpulkan data-data dari riwayat perbaikan kendaraan tersebut untuk dijadikan dasar dalam pembuat aplikasi administrasi perbaikan kendaraan.

\subsubsection{Studi Literatur}

Peneliti Mempelajari dan menggunakan literatur-literatur yang berhubungan dengan materi penelitian, baik berupa buku maupun jurnal dan situs-situs di internet untuk memberikan informasi yang dibutuhkan dalam pembuatan sistem. Literatur-literatur 
yang diambil dalam penelitian ini yaitu mengenai penelitian-penelitian terdahulu yang memiliki kesamaan topik penelitian, kajian teoritis mengenai apa itu sistem informasi, PHP, website, database, aplikasi dan literatur lainnya yang berhubungan dengan penelitian ini.

\subsubsection{Dokumentasi}

Mengecek dan mengumpulkan dokumen apa aja yang berkaitan dengan proses yang berjalan di departemen VOM, agar dapat mengevaluasi kekurangan dan kelebihan sebuah sistem yang akan dibangun.

2.1.5. Wawancara

Mengumpulkan pertanyaan dari beberapa departemen di PT. ALTRA 1978, dengan cara mengajukan pertanyaan langsung perihal peoses yang berjalan pada administrasi perbaikan kendaraan. Berikut pertanyaan yang diajukan:

a. Kendala apa yang dihadapi selama ini pada proses permintaan perbaikan kendaraan?

b. Apa tanggapan anda tentang proses administrasi perbaikan saat ini (sebelum adanya system)?

c. Apa harapan anda kedepannya khususnya untuk proses permintaan perbaikan kendaraan (sebelum adanya system)?

\subsection{Metode Pengembang Sistem}

Untuk metode pengembangan sistem menggunakan metode prototype. Adapun tahapan-tahapan perancangan yang akan dibuat dengan metode ini adalah sebagai berikut:

2.2.1. Identifikasi kebutuhan pengguna

Pada tahapan ini adalah menganalisis kebutuhan dari sistem informasi yang akan dibangun, seperti menganalisis:

a. Analisis kebutuhan user

b. Analisis kebutuhan VOM

c. Analisis kebutuhan warehouse

d. Analisis kebutuhan Section Head

\subsubsection{Membuat sebuah prototype}

Pada tahap ini dilakukan tahap perancangan pembuatan sistem mulai dari Flow of Document (FOD) yang diusulkan, Context Diagram (CD), Data Flow Diagram (DFD) hingga Entity Relationship Diagram (ERD).

\subsubsection{Evaluasi prototype}

Pada tahap ini model sistem akan dievaluasi dan dimodifikasi berulang-ulang hingga dapat diterima oleh pengguna sistem dan dirasakan pengguna telah sesuai dengan kebutuhan.

\subsubsection{Pengkodean Sistem}

Dalam tahap ini prototype yang sudah disepakati kemudian diterjemahkan ke dalam Bahasa pemograman yang sesuai dengan software progamming untuk menghasilkan sistem yang sudah dirancang.

\subsubsection{Metode Pengujian Black Box}

Metode pengujian sistem yang akan digunakan adalah pengujian black box. Pengujian black box ini berusaha menemukan kesalahan dalam beberapa kategori [6], yaitu:

a. Fungsi-fungsi yang salah atau hilang

b. Kesalahan interface

c. Kesalahan dalam struktur data atau akses basis data eksternal

d. Kesalahan inisialisasi dan teriminasi

2.2.6. Evaluasi sistem

Setelah proses pengkodean maka selanjutnya adalah proses evaluasi sistem dimana pengembang akan mempresentasikan aplikasi yang telah dibuat kepada pengguna, jika pengguna menyatakan setuju dengan hasil pengkodean maka aplikasi akan diimplementsikan, jika sebaliknya maka pengembang harus kembali ke langkah pengkodean.

\subsubsection{Penggunaan sistem}

Pada tahap ini dapat dikatakan aplikasi sudah mencapai $95 \%$ dan dapat dioperasikan dalam sistem. Pengembang akan memulai pelatihan kepada pengguna agar dapat menggunakan atau mengoperasikan apliksi.

\section{Hasil Penelitian}

Pembahasan akan dilakukan sesuai tahapan pada metode prototype, sebagai berikut:

\subsection{Analisis Kebutuhan Pengguna}

Melakukan analisis terhadap proses administrasi perbaikan kendaraan dengan melakukan komunikasi kepada pihak yang berkaitan dengan proses tersebut dan kemudian mengumpulkan informasi yang dibutuhkan untuk mengolah sistem yang sesuai dengan kebutuhan pengguna. Pihak yang terkait dalam proses ini ialah pengguna 
kendaran, departemen Vehicle Operation Management (VOM), Warehouse dan Section Head VOM.

Dalam proses administrasi perbaikan kendaraan, pihak pengguna kendaraan melaporkan kerusakan kendaraan kepada departemen Vehicle Operation Management dengan menggunakan form yang telah disediakan oleh perusahaan. Setelah menerima form tersebut VOM akan memeriksa kendaraan sesuai permintaan yang diberikan oleh penggunna tersebut, jika ada kerusakan pada kendaraan pihak VOM akan melakukan perbaikan dan jika pada saat dilakukan perbaikan membutuhkan penggantian spare part pihak VOM akan melakukan permintaan spare part menggunakan form permintaan part kepada pihak Warehouse, setelah spare part tersebut diterima oleh VOM, maka akan langsung dilanjutkan perbaikan kendaraan oleh VOM hingga perbaikan tersebut selesai. Setelah VOM melakukan beberapa perbaikan dalam 1 bulan, maka VOM wajib melaporkan setiap perbaikan kepada Section Head VOM. Laporan perbaikan kendaraan diproses menggunakan aplikasi Microsoft excel dan kemudian dikirim melalui email kepada Section Head VOM.

\subsection{Membangun Prototype}

Membangun prototype dengan membuat perancangan sistem yang akan diusulkan terkait sistem administrasi perbaikan kendaraan pada Vehicle Operation Management di PT ALTRAK 1978 Samarinda. Pada kegiatan proses administrasi perbaikan kendaraan akan menggunakan aplikasi berbasis web, dimulai dari proses melaporkan kerusakan kendaraan, proses permintaan perbaikan dan permintaan spare part hingga proses pelaporan hasil perbaikan kendaraan akan menggunakan aplikasi berbasis web. Pada PT ALTRAK 1978 khususnya pada departemen VOM membutuhkan sebuah sistem atau aplikasi untuk dapat melakukan proses administrasi perbaikan secara terpusat dan memudahan pengguna kendaraan saat ingin melaporkan kerusakan kendaraan kepada VOM, serta dapat memudahkan VOM dalam mengecek histori perbaikan dan melaporkan hasil perbaikan kendaraan karena setiap proses perbaikan akan masuk dalam sistem administrasi perbaikan kendaraan operasional PT ALTRAK 1978. Sesuai dengan penjelasan diatas mengenai proses aplikasi yang diusulkan, maka akan dibuatkan gambaran proses tersebut. Dalam proses tersebut ada beberapa alur atau tahapan mulai dari pengguna kendaraan melaporkan kerusakan kendaraan hingga proses laporan kepada Section Head. Dan berikut gambaran dari proses sistem yang akan diusulkan:

\subsubsection{Flow of Document yang diusulkan}

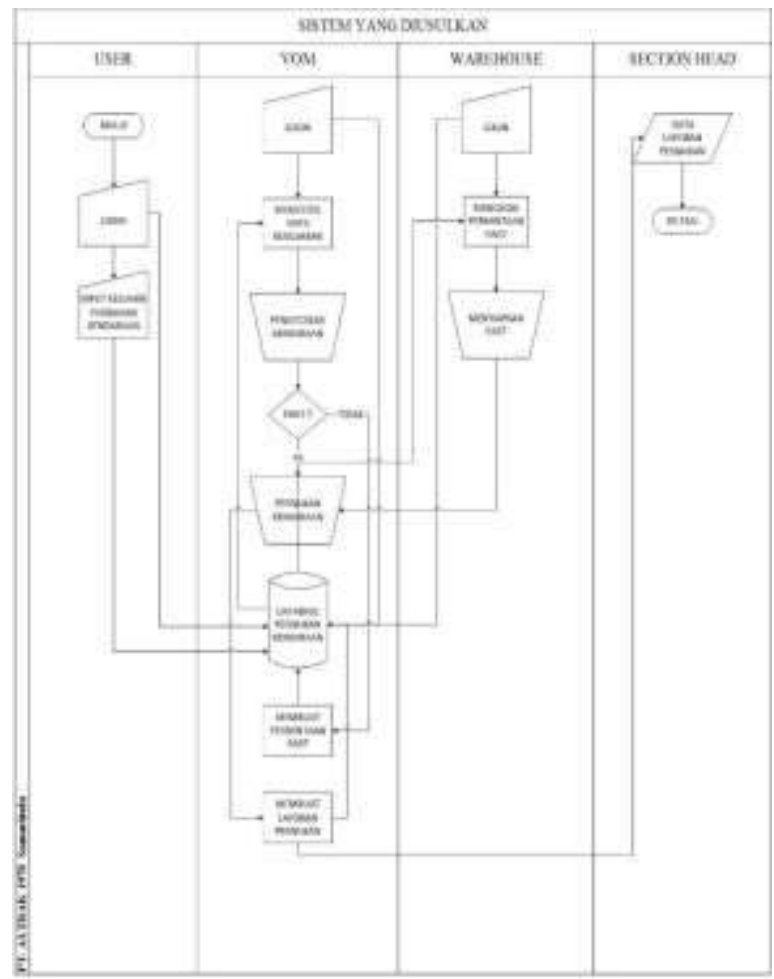

Gambar 1. Flow of Document yang diusulkan

Sesuai dengan gambar diatas mengenai proses sistem yang diusulkan. maka berikut adalah penjelasan dari gambar di atas:

a. User akan login dan kemudian akan mengisi keluhan perbaikan kendaraan pada aplikasi Vehicle Operation Management.

b. Berdasarkan data keluhaan kendaraan dari user, VOM akan login dan mengecek data permintaan perbaikan dari user pada kendaraan tersebut, kemudian VOM akan mengecek kendaraan sesuai laporan kerusakan, jika tidak memerlukan part maka akan langsung diperbaiki dan jika perbaikan tersebut memerlukan part maka VOM akan membuat permintaan 
part pada aplikasi Vehicle Operation Management, kemudian Warehouse akan mengecek permintaan part melalui sistem tersebut, setelah mengecek permintaan part, Warehouse akan menyiapkan part yang dibutuhkan dan akan diberikan kepada VOM. Setelah menerima part, VOM akan langsung memperbaiki kendaraan tersebut, jika perbaikan sudah selesai VOM akan membuat laporan perbaikan kendaraan dan akan dilaporkan kepada Section Head.

c. Warehouse akan login dan mengecek permintaan pada aplikasi dan menyiapkan part yang dibutuhkan.

d. Section Head akan memeriksa laporan yang telah dibuat oleh VOM.

\subsubsection{Context Diagram}

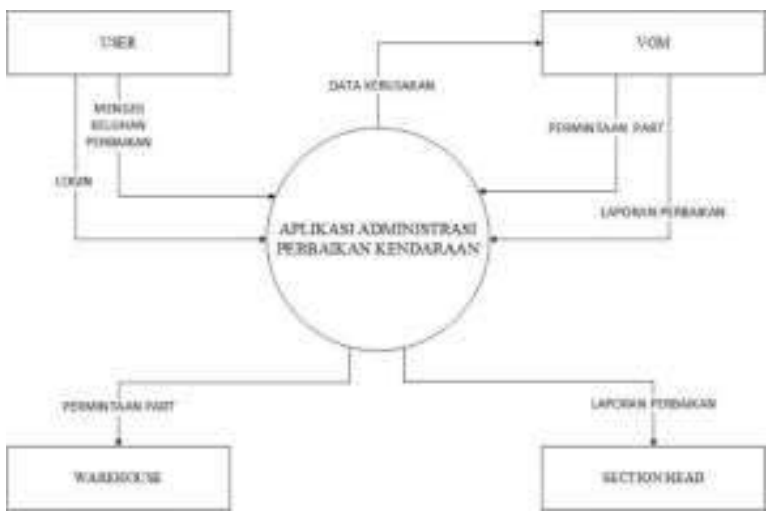

Gambar 2. Context Diagram aplikasi yang diusulkan

\subsubsection{Data Flow Diagram (DFD)}

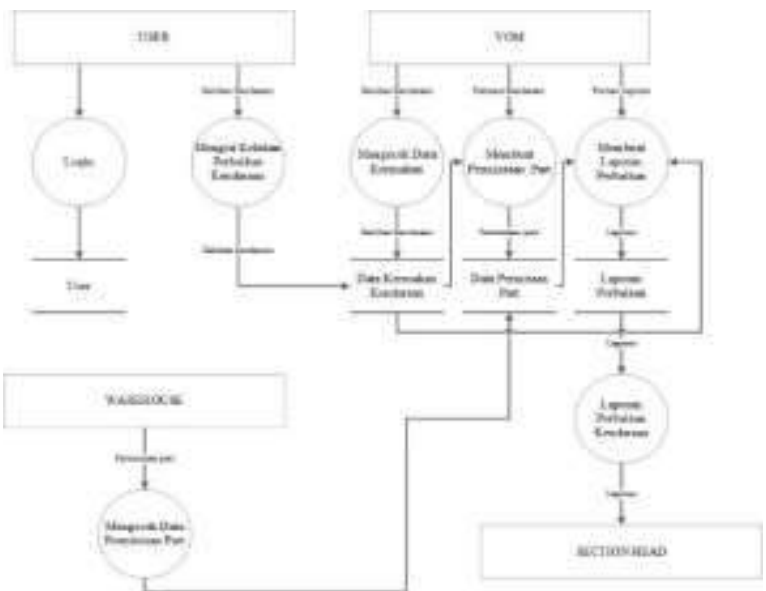

Gambar 3. Data Flow Diagram (DFD) yang diusulkan
3.2.4. Entity Relationship Diagram (ERD)

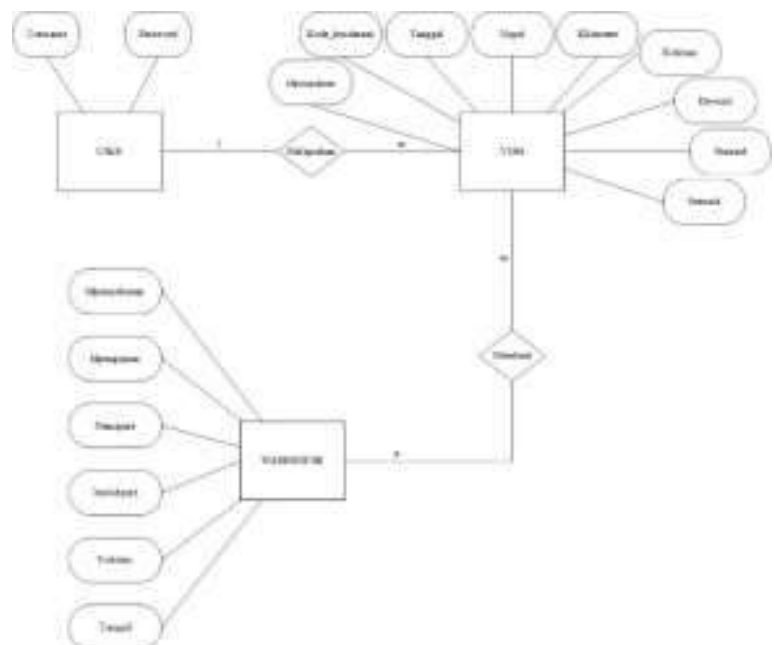

Gambar 4. Entity Relation Diagram yang diusulkan

3.2.5. Spesifikasi Basis Data

Tabel 1. Tabel Login

\begin{tabular}{cccl}
\hline Field & Type & Value & Descripsion \\
\hline Username & varchar & 10 & Primary key \\
Password & varchar & 15 & - \\
\hline
\end{tabular}

Tabel 2. Tabel Pengajuan Perbaikan

\begin{tabular}{llll}
\hline \multicolumn{1}{c}{ Field } & \multicolumn{1}{c}{ Type } & Value & Descripsion \\
\hline $\begin{array}{l}\text { Idpengajuan } \\
\text { Kode_kendaraan } \\
\text { Tanggal }\end{array}$ & integer & 11 & Primary key \\
varchar & 15 & Foreign key \\
Nopol & varchar & 15 & \\
Kilometer & integer & 11 & \\
Keluhan & text & & \\
Divisiid & integer & 11 & \\
Statusid & integer & 11 & \\
Tindakan & Text & & \\
& & & \\
\hline
\end{tabular}

Tabel 3. Tabel perbaikan dan permintaan part

\begin{tabular}{llll}
\hline \multicolumn{1}{c}{ Field } & Type & Value & Descripsion \\
\hline Idpermohonan & integer & 11 & Primary key \\
Idpengajuan & integer & 11 & Foreign key \\
Namapart & varchar & 15 & \\
Jumlahpart & integer & & \\
Terkirim & integer & 11 & \\
Tanggal & date & & \\
\hline
\end{tabular}

\subsubsection{Rancangan Desain Layout}

Berikut rancangan layout aplikasi administrasi perbaikan kendaraan pada PT ALTRAK 1978, berikut tampilannya: 
a. Halaman Login

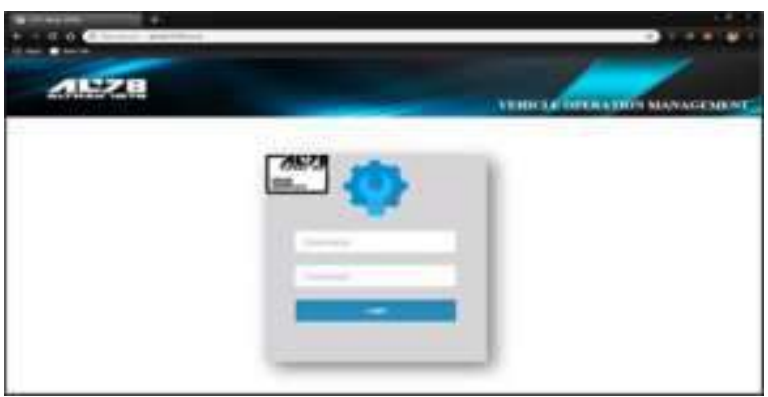

Gambar 5. Halaman Login

b. Halaman Pengajuan Perbaikan

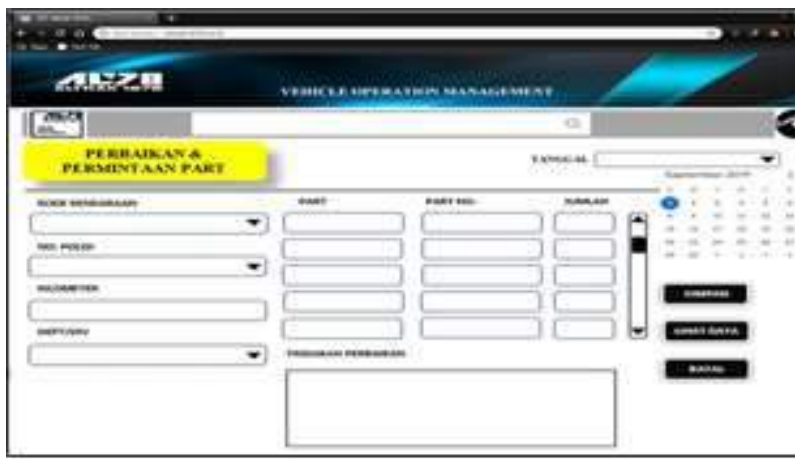

Gambar 6. Halaman Pengajuan Perbaikan

c. Halaman perbaikan dan permintaan part

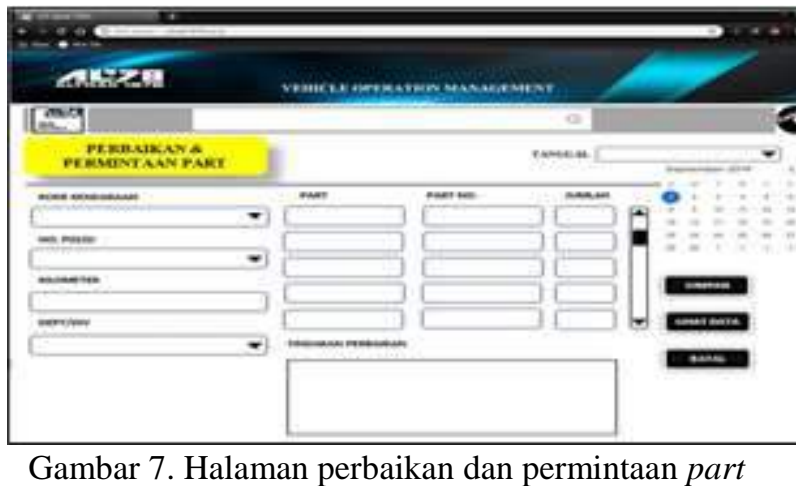

\subsection{Evaluasi Prototype}

\subsection{Implementasi sistem}

3.4.1. Implementasi perangkat lunak

Untuk mendukung aplikasi yang diusulkan berjalan dengan optimal, dibutuhkan perangkat lunak pengolah data, adapun perangkat lunak yang digunakan untuk mendukung pembuatan program aplikasi ini sebagai berikut:

1). Windows 10 Pro 64bit

2). XAMPP v.3.2.2

3). Subline Text 3

4). Bootstrap

5). Microsoft Visio
6). Adobe XD

7). Microsoft Word

\subsubsection{Implementasi User Interface}

a. Tampilan Login

Halaman login berfungsi untuk masuk ke halaman akses selanjutnya ke aplikasi perbaikan kendaraan pada Vehicle Operation Management.

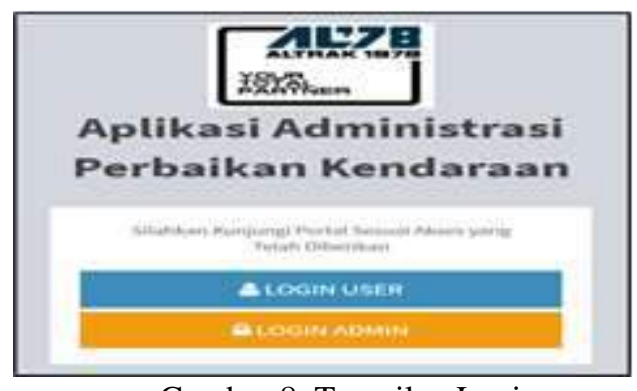

Gambar 8. Tampilan Login

b. Tampilan Form Permintan Perbaikan Kendaraan

Pada Halaman Form Permintan Perbaikan Kendaraan, User dapat mengisi keluhan atau kerusakan apa saja pada kendaraan yang untuk melaporkan kerusakan kepada VOM.

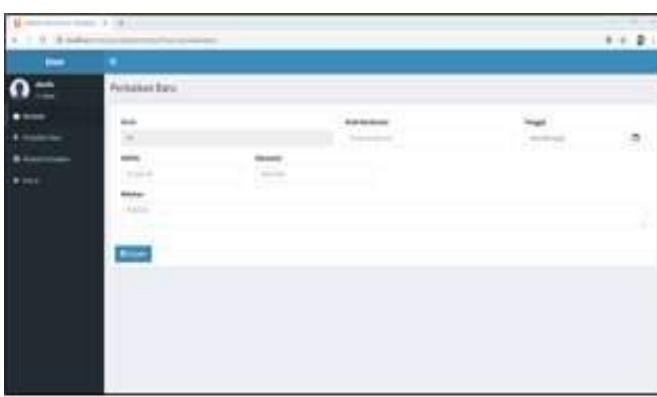

Gambar 9. Tampilan Form Permintaan Perbaikan Kendraaan

c. Tampilan Form Perbaikan dan Permintaan Part

Pada Halaman Form Perbaikan dan Permintaan Part admin VOM dan Warehouse dapat melihat kerusakan apa yang dilaporkan oleh user dan dapat mengisi apa yang diperbaiki dan dikerjakan serta apa saja spare part yang dibutuhkan. 


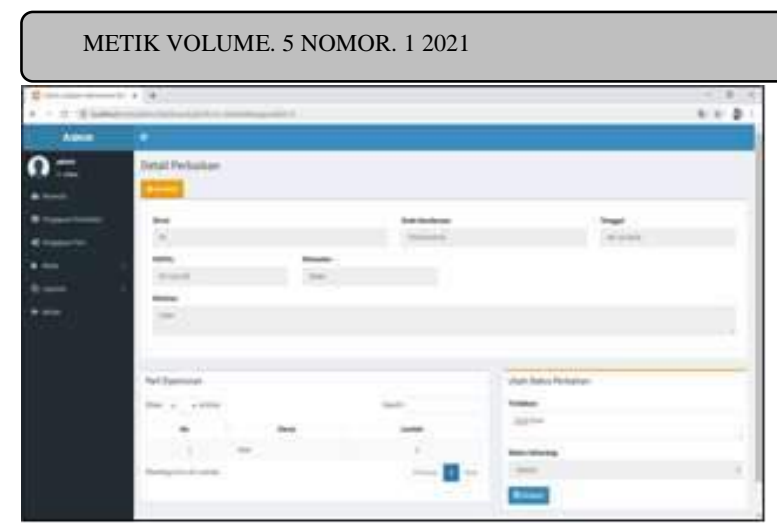

Gambar 10. Tampilan Form Permintaan dan Perbaikan Kendaraan

d. Tampilan Laporan Perbaikan dan Permintaan Part

Pada Halaman Laporan Perbaikan dan Permintaan Part, admin VOM dapat mengisi dan membuat laporan terkait perbaikan kendaraan dan spare part apa saja yang digunakan. Kemudian dilaporkan kepada Section Head.

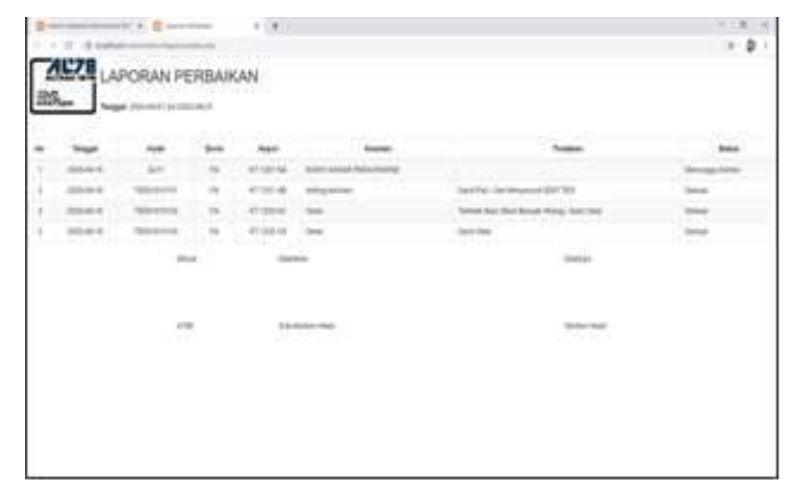

Gambar 11. Tampilan Laporan Perbaikan Kendaraan

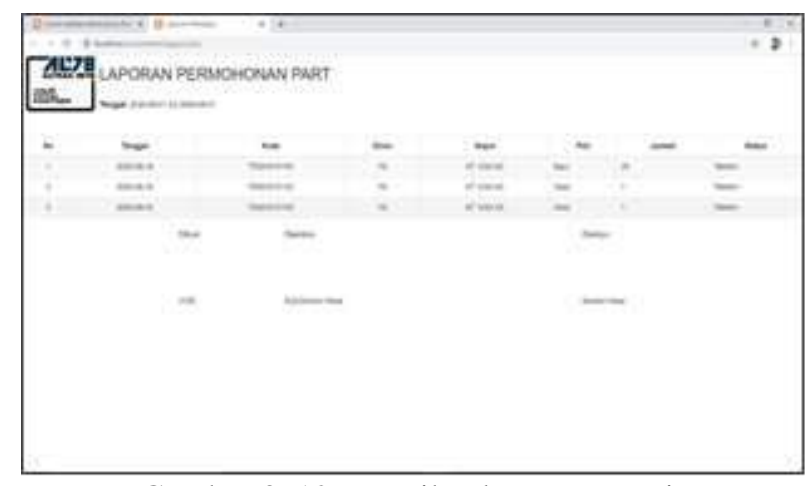

Gambar 3.12 Tampilan laporan permintaan part

\subsection{Pengujian Sistem}

Pengujian sistem dilakukan seperti pada tabel berikut.
Tabel 4. Pengujian Sistem

\begin{tabular}{|c|c|c|c|}
\hline Kebutuhan & $\begin{array}{l}\text { Data } \\
\text { masukkan }\end{array}$ & $\begin{array}{l}\text { Hasil yang } \\
\text { diharapkan }\end{array}$ & Keterangan \\
\hline Login & $\begin{array}{l}\text { Data User } \\
\text { Data VOM } \\
\text { Data } \\
\text { Warehouse }\end{array}$ & $\begin{array}{l}\text { User dapat } \\
\text { login. } \\
\text { VOM } \\
\text { dapat login. } \\
\text { Warehouse } \\
\text { dapat login. }\end{array}$ & $\begin{array}{l}{[\sqrt{ }] \text { Diterima }} \\
{[\text { ]Ditolak }}\end{array}$ \\
\hline Input Data & $\begin{array}{l}\text { Data } \\
\text { Permintaan } \\
\text { Perbaikan } \\
\text { Data } \\
\text { Perbaikan } \\
\text { dan } \\
\text { Permintaan } \\
\text { Part } \\
\text { Data } \\
\text { laporan }\end{array}$ & $\begin{array}{l}\text { Berhasil } \\
\text { menginput } \\
\text { data }\end{array}$ & $\begin{array}{l}{[\sqrt{ }] \text { Diterima }} \\
{[] \text { Ditolak }}\end{array}$ \\
\hline $\begin{array}{l}\text { Simpan } \\
\text { Data }\end{array}$ & $\begin{array}{l}\text { Data } \\
\text { Permintaan } \\
\text { Perbaikan } \\
\text { Data } \\
\text { Perbaikan } \\
\text { dan } \\
\text { Permintaan } \\
\text { Part } \\
\text { Data } \\
\text { laporan }\end{array}$ & $\begin{array}{l}\text { Berhasill } \\
\text { menyimpan } \\
\text { data }\end{array}$ & $\begin{array}{l}{[\sqrt{ }] \text { Diterima }} \\
{[\text { ]Ditolak }}\end{array}$ \\
\hline
\end{tabular}

\section{Kesimpulan}

Dari berbagai penjelasan yang telah diuraikan dalam laporan ini maka dapat disimpulkan berbagai hal sebagai berikut:

a. Dengan adanya aplikasi administrasi perbaikan kendaraan berbasis web ini agar dapat memudahkan VOM untuk melakukan pelaporan perbaikan kendaraan dengan sumber data atau histori perbaikan dapat dilihat dan diambil dengan mudah.

b. Merancang aplikasi administrasi perbaikan kendaraan yang dilakukan secara komputerisasi dan data perbaikan kendaraan dapat terintegrasi antara beberapa departemen yang berhubungan langsung dengan proses perbaikan kendaraan.

c. Tampilan dari aplikasi sangat mudah untuk dipahami serta user dapat melaporkan kerusakan kendaraan kepada VOM dengan mudah dan cepat.

\section{Saran}

Dengan terselesaikannya Rancang Bangun Aplikasi Administrasi Perbaikan Kendaraan Pada Vehicle Operation Management Berbasis Web Di PT. Altrak 1978 Samarinda, ada beberapa saran yang 
dapat diberikan untuk pengembangan atau perbaikan selanjutnya sehingga aplikasi ini dapat membantu perusahaan, antara lain sebagai berikut:

a. Diharapkan adanya penelitian lebih lanjut dikarenekan masih banyak kekurangan pada aplikasi yang telah dibuat oleh peneliti.

b. Adanya penerapan aplikasi administrasi perbaikan kendaraan pada vehicle operation management.

c. Diharapkan aplikasi administrasi perbaikan kendaraan pada vehicle operation management ini nantinya dapat dikembangkan sesuai kebutuhan yang diperlukan oleh PT ALTRAK 1978 Samarinda.

\section{Daftar Pustaka}

[1] T. Sutabri, Konsep Dasar Sistem Informasi, Yogyakarta: Andi, 2012.

[2] A. Rudyanto , Pemrograman Web Dinamis Menggunakan PHP dan MYSQL, Yogyakarta: CV. ANDI OFFSET, 2011.

[3] A. F. Sibero, Web Programming Power Pack, Yogyakarta: Mediakom, 2013.

[4] T. Arifin and H. Rahmat, Statistika Penelitian, Bandung: Pustaka Setia, 2013.

[5] A. Zuhri, "Pengertian Perbaikan," 12 Maret 2020. [Online]. Available: http://www.aguszuhri26.blogspot.com/.

[6] Fahrullah,

"IMPLEMENTASI

PENGUJIAN BLACK BOX PADA SISTEM INFORMASI MONITORING AKADEMIK DENGAN PENDEKATAN TEKNIK EQUIVALENCE PARTITIONS," Jurnal Teknosains Kodepena, 2021. 